\title{
The Early Modern European Drama and the Cultural Net: Some Basic Hypotheses
}

The research project within which the conference whose proceedings are published in this volume took place ${ }^{1}$ has two main objectives, one historical, the other theoretical. In terms of literary and cultural history, it aims to undertake an analysis of (Western) European early modern drama as the first phenomenon of mass culture in human history. In terms of theory, it explores the metaphor of culture as a (virtual) network, with regard to the specific cultural field just mentioned and beyond.

The early modern age bears its name because the basis of modernity proper was cast in that period. This applies to science (think of the theoretical foundation of empiricism and of rationalism), religion (the establishment of [intra-Christian] religious pluralism as the main result of the Thirty Years War), political organisation (I am referring to the "invention" of the centralised and bureaucratic state), political theory (I am thinking here of the theory of absolutism, and of international law), the development of a pervasively allegorical understanding of Scripture (within certain Protestant denominations, but partly within Catholicism as well), and the conception of the world at large (the discoveries and the subsequent adoption of an experience-based model of world and cosmos), to name only the most important points. In all these respects, European societies crossed a threshold of global historical importance: the abandonment of cyclical conceptualisations of time and the establishment of the concept of (possibly never-ending) "progress." It was this conceptual distancing from the cyclical model that laid the foundations for the effective, material transformation of the world beginning in the eighteenth century, that is, massive industrialisation.

According to the dominant view, the changes in the cultural sphere in general and in the literary sphere in particular were much less radical. The overcoming

1 This volume is part of a larger collaborative research project funded by an Advanced Grant from the European Research Council (ERC). Within the project there are six doctoral thesis sub-projects and another six post-doctoral ("second book") sub-projects focusing on specific aspects of the question addressed by the larger research project; in addition, there are five volumes presenting the proceedings of the conferences organized by the DramaNet reaearch project. I elaborate on the concepts outlined in this essay in my book The Cultural Net: Early Modern Drama as a Paradigm (Berlin/Boston: De Gruyter, 2018; Open Access)

2 On this point see my essay “The Traditional Cosmos and the New World," Modern Language Notes 118 (2003), pp. 363-392. 
of medieval cultural patterns is supposed to have largely taken the path of re-activating an already existing paradigm, the culture of classical antiquity ("Renaissance"), blending it with a limited set of "new" ideas. Early modern culture would thus have to be subsumed under an age that begins already at the end of the fourteenth century. Cultural modernity proper-understood as the emancipation from culture as cyclical recurrence-would thus begin only during the age of Enlightenment or rather with the age of Romanticism and its anti-classical, anti-normative turn as well as its positing, for the first time in human history, of art as autonomous. Early modern literary culture would be, as it were, belated with regard to contemporary scientific progress, philosophical achievements, or even religious "pluralisation."

Early modern drama, however, is an apt example for showing that these current views neglect important, even crucial traits of the cultural dynamics of that period. Sixteenth- and seventeenth-century European drama was, indeed, inspired by classical models (mainly Terence and Seneca) and by classical poetology (neo-Aristotelianism). Nevertheless, it differs fundamentally from its classical "sources." In that period, drama as performance established the basis of what has become the main element of present-day culture, occidental and non-occidental: visual culture as mass media. This most significant "leap" in terms of cultural practices may be observed in all major European countries with slight differences regarding periodisation: first in England, then in Spain, some decades later in France and Germany. The pre-history of the corresponding development is to be found in early sixteenth-century Italy, where one can rightly speak of a "Renaissance," as we are dealing mainly with a revival of classical models. The new cultural pattern spread rapidly to other western and central European countries (the Low Countries and Scandinavia, Portugal, Poland and the non-German-speaking parts of the Habsburg Empire), where it came in contact with a partially still existing "local" theatre tradition, which goes back to the shared European tradition of medieval Christian drama (moralities and mysteries). ${ }^{3}$

The main common characteristic of works of early modern drama is that they are written with the aspiration of being performed on stage, thus differing from Renaissance drama, which was written mainly to be read (as, e.g., the most

3 The nomenclature for the sub-genres of medieval didactic drama differs from one vernacular to another, but in all the relevant "national" theatre cultures there is the bi-partition designated by the English terms used above, namely, dramas that are mainly moralising and make use of the device of allegory (mostly in the sense of personifications of vices and virtues) and, secondly, dramas that present the miracles and mysteries from Biblical history and the saints' and martyrs' lives. 
famous drama text of that period, the Celestin $a^{4}$ ). This entails a radical change of audiences. Early modern drama addressed highly diverse audiences, from the illiterate class to the intellectuals and the nobility. As such, its themes and objectives underwent a fundamental transformation: the highly refined and elitist Renaissance culture was replaced by a mass culture, a phenomenon that will affect the other genres, mainly narrative, only in an age when literacy became ubiquitous, i.e. in the nineteenth century.

Court theatre, which emerged at the end of the fifteenth and the beginning of the sixteenth centuries, continues to exist, but becomes a more and more recessive phenomenon. "Regular" early modern drama is either performed in institutionalised play-houses and on play-grounds, depending on climate conditions, or on carts, by itinerant companies. Performances are public in the sense that everyone who is ready to pay an (affordable) fee is admitted. The comparison with religious drama in the strict sense, which still exists in certain countries-mainly Spain-allows the most important difference to be determined between early modern drama and the medieval drama performances, which were commonly accessible as well but became restricted because they were bound to the festivals of the Christian calendar, primarily Christmas and Easter. The theatre created in the sixteenth century establishes for the first time in human history the cultural practice of a public visual culture that is not bound to ritual patterns (religious or political, as was the case in classical Athens) and the ensuing constraints.

The research conducted on European early modern drama has been confined to the companion-style type of monograph so far. Existing monographs on the European drama of that age largely lack a discussion of extra-literary discourses that ought to be considered. They follow traditional patterns of literary history in the narrow sense, including at best some commonplace remarks regarding staging. Numerous journal articles with a comparative focus are mostly restricted to a more or less updated variant of motif history or to comparisons between single works of specific authors. Highly sophisticated new approaches to great dramatic authors of that age, such as, e.g., Stephen Greenblatt's publications on the Elizabethan theatre, ${ }^{5}$ have considered the questions raised by early modern

4 As to the intellectual depth of the Celestina, which is from my view one of the most relevant texts of European early modernity, see my "Mittelalterlich kosmische Ordnung und rinascimentales Bewußtsein von Kontingenz: Fernando de Rojas' Celestina als Inszenierung sinnfremder Faktizität (mit Bemerkungen zu Boccaccio, Petrarca, Macchiavelli und Montaigne)," in: Gerhart von Graevenitz and Odo Marquardt, edd., Kontingenz (München: Fink, 1998), pp. 152-173.

5 Stephen Greenblatt, Shakespearean Negotiations: The Circulation of Social Energy in Renaissance England (Oxford: Clarendon Press, 1988). 
theatre from the perspective of one particular "national" culture; exogenous sources, mainly Italian and French, are taken into consideration, if applicable, but the perspective as a whole is not comparative. This applies as well, mutatis mutandis, to Antonio Maravall's research on the Spanish Golden Age drama. ${ }^{6}$ Maravall considers the corral theatres as part of a propaganda system; that is in principle a hypothesis worth being considered, but his focus on Spanish drama of that age entails certain limitations with regard to this thesis. Walter Benjamin's essay on German baroque drama is still a source of inspiration, ${ }^{7}$ as is Albrecht Schöne's monograph on emblem books and German baroque drama, ${ }^{8}$ which was the first publication to draw attention to the close links between drama and the visual culture of that age. - So far, however, there has been no systematic discussion of early modern drama as a phenomenon pertaining to the entirety of western and central European societies of that age. The main desiderata of the DramaNet project are: 1) a thoroughly comparative perspective; 2) a consideration of drama/theatre beyond the confines of literary discourse in the traditional sense; 3) a "strong" hypothesis regarding the societal function of early modern drama; 4) an integration of the data available in the cultural field into the general historical dynamic of that age: the rise of England and France, decay of Spain, contradictory tendencies, but mainly stagnancy in the rest of Europe, including the German territories.

In terms of theory, the project is investigating the productivity of the metaphor of culture as a virtual network. The metaphor is conceived in the first place with regard to this specific field, early modern drama, but its aims at the same time go beyond the limits of the age and the genre that are the focal points of this project.

Post-modernist theorising of larger cultural contexts replaced the structuralist standard metaphor of the tree by the metaphor of the rhizome (Deleuze/ Guattari). ${ }^{9}$ The main progress in this replacement was the overcoming of the concepts of strictly defined hierarchies and of unidirectional processes that are implied by the tree metaphor. The problem inherent to the rhizome concept is that it seems to suggest a "naturalistic," biology-inspired model of cultural processes, which nevertheless may follow a logic that is independent of the general patterns of the evolution of life. Cultural artefacts differ from biological entities

\footnotetext{
6 José Antonio Maravall, Teatro y literatura en la sociedad barroca (Barcelona: Ed. Crítica, 1990). 7 Walter Benjamin, The Origin of German Tragic Drama [Ursprung des deutschen Trauerspiels, 1928], trans. John Osborne (London: Verso, 1977).

8 Albrecht Schöne, Emblematik und Drama im Zeitalter des Barock (München: Beck, 1964).

9 Gilles Deleuze and Félix Guattari, A Thousand Plateaus: Capitalism and Schizophrenia, trans. Brian Massumi (Minneapolis: University of Minnesota Press, 1987), pp. 3-25.
} 
in that they do not necessarily follow a pre-stabilised programme (encoded in the genes), but are rather subject to relatively free decisions made by humans. ${ }^{10}-$ The rhizome concept, whose provisional merits shall not be contested, may have its weakest point in being still all too structuralist, notwithstanding its claims to being post-structuralist: a rhizome is a non-hierarchical, de-centred structure; on the other hand, however, it is an on-going replication of one basic pattern that remains identical to itself during the processes of replication. - The third point to be raised critically is the question of the transformation of (visible) forms, that is, of entities consisting of large quantities of elementary units. In the realm of biological life these transformations occur, but the mutation of genes and the possibly ensuing coming into being of new species are relatively rare; they happen within chronological frames that transcend the regular human existence. Culture, on the other hand, is characterised by rapid and erratic change in phenomena; if there is stability at all, it is to be found neither in the pheno- nor in the genotype, but rather in function. - In short, if the notion of rhizome is applied to the cultural sphere, its shortcomings are the problem of agency, the overestimation of standardising with regard to the elementary units of cultural structures and the undervaluation of morphic change as a distinctive characteristic of cultural evolution.

The metaphor, or rather, metonymy of circulating social energy introduced by Stephen Greenblatt with regard to modelling cultural processes has the advantage of accounting for the high degree of flexibility of the corresponding processes. The risks implied by this concept seem to converge in two points: the question of whether such circulation happens freely, according to a largely non-causal logic (contingency) and on behalf of an immanent propulsive potential of the material concerned ("social energy") or whether it is dependent on structures that enable it to a greater degree than is suggested by the assumption of an inherent energy. The latter alternative points towards the complex of questions revolving around the problem of agency: such structures may be established or not; they may be enhanced or rather be restricted; they may be extended or rather interrupted. - The high relevance of the problem of agency and especially of exerting pressure, in one way or another, on the circulating social energies becomes all the more visible as one transcends the analysis of "national" circuits: how are we to account for the incontestable differences to be observed with regard to, e.g., early modern English and Spanish drama (theatre,

10 I do not wish to engage here with the discussion of whether "free will"/ "free decisions" are illusions by which we try to hide from ourselves that we are only carrying out natural programmes; making culture my theme, I will stick to observable surface phenomena and consider nothing but the observable logic of their development. 
respectively)? What is "different" in the processes of circulation and where does the difference originate from? And, perhaps the most important point: what are the consequences of these differences, with regard to culture in the narrow sense (literature and, in this case, theatre) and with regard to culture at large, that is, society? - The second point in Greenblatt's approach that might be worth reconsidering is that he posits the "separation of artistic practices from other social practices."11 This separation is crucial with regard to the recipients' perspective (the most famous narrative text of that age, the Quijote, deals exactly with this problem, in the sense that it presents a hero who seems to be not capable of or not willing to operate this separation). But to what extent should we separate artistic material and other cultural material with regard to processes of transfer and circulation? Of course, there is a separation as far as the materialised forms are concerned; paintings and "pragmatic" manufactured goods may travel on one ship, but as material forms they are distinct and travel as distinct items. This separation seems much more difficult to establish in terms of conceptual forms: what exactly is transferred when a dramatic text is "exported" to another country or even just to another town within the same country? Firstly, of course, a specific text, but along with it, as shall be argued here, all the non-artistic cultural forms and concepts it is made up of (philosophical, theological, anthropological, juridical, political discourses, etc.). Cultural dynamics are to a large extent based on this specific feature: organised forms (“works," artistic as well as non-artistic) are not only transported themselves, but rather along with the whole range of cultural material they contain. - The main desiderata of the DramaNet project with respect to theory are: 1) a concept that accounts for the specificity of cultural processes with regard to "natural" processes; 2) a model that enables and favours transnational comparisons; 3 ) an approach that allows for an adequate consideration of the problem of agency, and 4) a frame that opens up possibilities for the discussion of literary phenomena as simultaneously separate from and part of a larger discursive scenario, or cultural practices respectively.

The DramaNet project is an attempt to move beyond the existing concepts just referred to by investigating the explanatory potential of the metaphor I indicated above. I will briefly outline the main implications of this new concept.

A network is a non-hierarchical structure without a centre. It does not originate spontaneously, however, or by means of an extra-human, evolution-driven process. It is produced by humans and created for intention-driven purposes. These intentions may be fulfilled or not. If they are not fulfilled, the net may be destroyed by those who constructed it. Very frequently, though, network

11 Greenblatt, Shakespearean Negotiations, pp. 12 f. 
structures that do not evolve according to initial expectations assume other, often unforeseen and in that sense potentially "revolutionary" functions. - As soon as they exist, even net structures functioning according to initial purposes come to transport not only the material for the circulation of which they were created, but other, at times completely heterogeneous material as well. This happens frequently without being noticed, at least for some time. "Innovation" is in most cases a consequence of such an unnoticed transfer of heterogeneous material that would have been rejected, had it been noticed.

Network structures may be set up everywhere and anywhere. Apart from the will to set them up, they do not need any further specified substratum. The only requirement is to have the means (money, labour force) to construct and entertain them. A net has no entelechical form. Networks are never complete. They are not created once and for all. Net structures may thus extend and ramify to regions completely unknown to those who set them up initially.

Cultural networks are a specific variant of network structures. They may have a stable material substratum or not; in any case, they need a material substratum, but not necessarily a stable one. "Culture" in this context is conceived in the broadest possible way, that is, in the etymological sense (from Lat. colere) of all activities by which humans transform the nature-given habitat. Culture understood as a specific trait of humans differs from elementary processes of customising the natural habitat that can be observed with animals, in the sense that it exists in two different registers bound to each other-as material forms and as conscious concepts that inform the respective forms or can be extrapolated from them. The cultural net primarily contributes to transferring these conceptual forms. The material forms may "travel” as well (paintings, statues, books), but not necessarily in order to produce cultural activity and exchange. - The circulation of conceptual forms also needs a material substratum in order to take place. Most frequently, this material substratum comprises circulating humans (merchants, warriors, courtiers or diplomats, future spouses, religious officials, academics, artists).

The movement of material mediated by cultural net structures is not unidirectional. It will remain to be explored whether this aspect can be better accounted for by conceiving cultural nets as being organised according to circuit structures or whether it is more apt to assume them to be shaped according to a highway pattern. The advantage of the latter alternative would be that in such a structure, inverse movement of the transferred material is possible but not compulsory, mandatory or necessary. Total reciprocity and complete absence of hierarchies as a feature of culture seems to be as problematic an assumption as the obsolete metaphor of culture as a tree.

Since they are constructed by humans, cultural network structures are subject to the human will for their transport capacity. They may be extended and 
enlarged, or, rather, parts of them may be enlarged. They may be restricted or interrupted temporarily, or even be destroyed completely. The material may be allowed to float freely, or it may be submitted to a more or less systematic scrutiny and then allowed to travel on or not, or partly so. Control agents are not contingent upon the material floating in the net, they obey an external logic. If control agents are not changed from time to time, they may be affected by the scrutinised material and thus fall short of their duties. The control logic may be belief-driven, power-driven or money-driven. It may be an illusion that movements within the cultural net are driven by "immanent" quality standards.

Typically, the types of control logics I have just apostrophised do not exist in "pure" versions, but as specific and varying constellations of the three components; in almost all observable cases, there are internal frictions between the components. Much cultural difference, in the age to be considered but in other ages and places as well, seems to result from differing overall control logics. In the early modern as in the present-day world, different concepts of what the "right" control logic is or should be may have led and may still lead to "culture clashes."

Circulating material may be withdrawn from the net at any given point. As soon as withdrawn, the material is shaped into formally defined entities by humans (individuals or groups of humans). In case the material is language-based, the first step of this formal shaping is the homogenising of differing symbolic codes (languages). The levels of further formal organisation typically attained differ dramatically. The formal entities ("works") are then "used" with regard to different functions, mainly didactics, entertainment and reflection.

Since they exist in a material as well as in a conceptual mode, the formal entities originating from the cultural net are inconsumable. After having been "used" they continue to exist, in some cases both in the material and the conceptual mode (paintings, books), but in any case in the conceptual mode. They are then re-absorbed by the material floating in the net and continue their potentially endless travel.

As is true with regard to "physical" nets (e.g. road networks), the floating material may circulate in different degrees of formal organisation, from the level of "raw material" up to the level of organised entities capable in certain cases of being auto-motive within the net. The fact that the material floating in cultural nets is not homogeneous (in the sense of not being formally standardised) is a plea for discarding the metaphors of web or grid that could be considered as well. Highly organised entities may keep that level of formal consistency when reabsorbed by the net after having been used, or may be decomposed into the components out of which they were assembled.

Literary texts would, according to this perspective, become a configuration of cultural material organised with regard to all three functional dimensions 
mentioned above (didactics, entertainment and reflection). The relative weight of each purpose would vary from work to work and would be subject to reassessment from the perspective of different recipients. Pragmatic cultural texts, ${ }^{12}$ in contrast, would be characterised by either one of these functions. There may be traces of the non-dominant functions in pragmatic texts as well (e.g. the pleasurable, in a way "entertaining" presentation of a philosophical text or of a religious sermon). This latter point and the aspect, mentioned above, that different purposes inform a literary text to different degrees may account for the affinities between certain literary and certain non-literary texts, mainly philosophical or religious. "Literature" as strictly distinct from the other discourses is not a phenomenon, it is an ideal concept, and we should even consider the possibility that it came up only with the rise of philosophical aesthetics (Kant, Critique of Judgment), that is, at the end of the eighteenth century.

What may be the possible results of such a new approach to early modern European drama? Firstly, it would automatically free the texts and the actual practices from being considered within the boundaries of national cultures. Evident common traits could be explained as originating from the participation in one common network structure and need no longer be explained by way of almost always highly speculative assumptions about this or that book having been available to this or that author at a given place in a given moment. Transculturality would thus become the standard case, "nationality" of cultural artefacts would be considered the particular case to be explained according to the control logics outlined above (mainly: power- or belief-driven attempts to restrict the floating material available at a given place at a given moment). Common traits between spatially or temporally separated works of art would no longer be difficult to explain. Reception in later times or in remote regions could be accounted for according to the three basic control mechanisms mentioned above. Circulating material may thus be considered exoteric or esoteric, depending on the times and places where it is assessed. Fundamental formal standards that can be observed in all European "national" cultures could be accounted for by considering the

12 I will not discuss the question of scientific texts nor of those texts, such as, e.g., political treatises, that first emerged as separate text corpora particularly in this period. All theoretical problems involved are addressed in a satisfactory fashion within Niklas Luhmann's thesis of modernity as a period of ever-growing functional specialisation, that is, as separation of discursive sub-fields, which in former periods constituted the one general discursive field (the latter term according to Michel Foucault, The Archaeology of Knowledge and the Discourse on Language [L'Archéologie du savoir, 1969], trans. A. M. Sheridan Smith [New York, NY: Pantheon Books, 1972], pp. 31-76; as to Niklas Luhmann see Observations on Modernity [Beobachtungen der Moderne, 1992], trans. William Whobrey [Stanford, CA: Stanford University Press, 1998]). 
floating of the material as taking place to differing degrees of formal organisation: "shaping" need not necessarily start at the basic level whenever a quantity of material is extracted from the net in order to be shaped. (Relative) difference with regard to form could be explained with the possibility of imposing whatever form on the material floating in the net.

Theatre performances are based on literary texts, or, at least, on a précis of a possible literary text. As cultural (arte)facts they differ, though, from texts. The reception situation is not individual, it is collective. The actual artefact is mediated by language and vision. Sound and, eventually, scent are additional channels of mediation. The shared experience of reception, the engagement of all the ("indirect") senses ${ }^{13}$ and the fusion of the arbitrary (symbolic) and the iconic sign systems result, with the recipient, in a sense of being overwhelmed or, rather, it is the major intention of the cultural practice we call theatre as well as of its modern variants, film and television, to bring about this effect.

The main characteristic of early modern drama as a cultural practice, that is, as theatre, is its historically unprecedented impact. It reaches a broad audience that neither traditional elitist nor popular culture could draw, and its being stripped of ritual contexts enhances the "emotional" impact on the individual recipient incommensurably; ritual performances, such as, e.g., religious drama or the ritual of religious service, entail processes of automatisation ${ }^{14}$ because of their repetitive structures. As such, early modern theatre is the site of an immensely increased speed as well as the intensification of processes of cultural transfer. Consequently, it may have been used to shape or reshape intra-individual and thus societal patterns of connecting cultural material ("mental habits," "mentalities").

On the other hand, as a non-ritual cultural practice, early modern theatre cannot rely on a pre-stabilised audience that would be obliged to attend, as, e.g., religious service could, at least in that age. Any attempt at shaping mentalities has thus to be based on structures of enticement. Visual effects ("magic," "marvel"), love and laughter are the cultural resourses typically extracted from the net in order to effect enticement. It is one salient trait of early modern drama as a mass medium that these resourses are combined indiscriminately with "serious" material extracted from the net (religious, philosophical, moral discourses). The boundaries of classical drama theory (Aristotle) are systematically transgressed; exceptions from this general rule (the French seventeenth-century stage) have to be carefully considered.

13 Meaning: with the exclusion of touch and taste.

14 In the sense of the term as introduced by the Russian formalists. 
The fact that it is dependent on language differentiates (early modern) theatre from other performative cultural practices that could be sensibly subsumed under the heading "mass culture" as well, such as e.g. ancient gladiator fights, medieval and Renaissance festival culture (courtly and popular) or modern sport events. One could perhaps come up with the thesis that events and performances with a mass appeal produce social cohesion as such, or are at least intended to do so. Theatre as a specialised variant includes language, that is: specific meaning. Language-based performative practices that are presented in order to be consumed by a given public are thus apt to produce cohesion and then to steer, as it were, the body social into one specific direction. It seems to be mainly the specificity of this steering capacity that differentiates theatre from the other performative practices mentioned above. ${ }^{15}$

The great experiment of an early mass culture was put into practice in different variants in different countries. In England it was an anticipation of phenomena that became ubiquitous in the twentieth century. France opted for a traditionally disciplined variant of drama during this period, keeping genres, and thus discourses and audiences, separate. Only comedy (Molière) was part of an all-encompassing, quasi-egalitarian mass culture as briefly characterised above. In Spain there is the remarkable phenomenon of an immensely successful theatre-as-mass medium, which was literally destroyed and cut off the cultural net by authoritarian means at the end of the seventeenth century. On the German stage of that age, there was little readiness to make use of the entire material circulating in the cultural net. Selection processes were executed in a particularly rigid way, and they were much more belief-driven than in other European countries of the time, with the exception of Poland.

15 Sport events, for example, could be conceived-beyond the integrative function, which seems characteristic of all performative practices-as instruments of implementing a spirit of competition amongst those who attend and watch. Gladiator fights may have a (highly desirable) "brutalising" function within the social and cultural structure of an empire based on physical, military force. Court festivals might implement an attitude of admiration with reference to the person who enabled them to take place, that is, the prince or monarch (etc.). 
